\title{
Correction to: Validation in the general population of a C-peptide estimate equation to measure beta cell function in recent-onset type 1 diabetes
}

\author{
Joanna Wang ${ }^{1} \cdot$ Naiara Bediaga ${ }^{2,3} \cdot$ Roberto Mallone $^{4,5} \cdot$ Etienne Larger $^{4,5} \cdot$ Leonard C. Harrison $^{2,3}$. \\ John M. Wentworth ${ }^{1,2,3}$. the ImMaDiab Study Group
}

Published online: 16 October 2020

(c) Springer-Verlag Italia S.r.l., part of Springer Nature 2020

\section{Correction to: Acta Diabetologica https://doi.org/10.1007/s00592-020-01604-7}

Authors would like to correct the first name of author Joanne Wang from Joanne to Joanna. Correct version of author name updated here.

The original article has been corrected.

Publisher's Note Springer Nature remains neutral with regard to jurisdictional claims in published maps and institutional affiliations.

The original article can be found online at https://doi.org/10.1007/ s00592-020-01604-7.

John M. Wentworth

wentworth@wehi.edu.au

1 Department of Diabetes and Endocrinology, Royal Melbourne Hospital, Parkville 3050, Australia

2 Walter and Eliza Hall Institute Department of Population Health and Immunity, 1G Royal Parade, Parkville 3052, Australia

3 Department of Medical Biology, University of Melbourne, Parkville 3052, Australia

4 Université de Paris, Institut Cochin, CNRS, INSERM, 75014 Paris, France

5 Service de Diabétologie Et Immunologie Clinique, Assistance Publique Hôpitaux de Paris, Hôpitaux Universitaires de Paris Centre-Université de Paris, Cochin Hospital, 75014 Paris, France 